\title{
LÍMITES ECONÓMICO-POLÍTICOS DE LA INTERVENCIÓN ESTATAL
}

\section{Presentación}

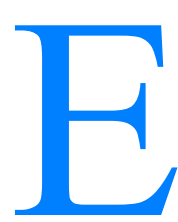

sta ponencia trata de eludir la confrontación entre dos teorías normativas: por un lado, el utilitarismo clásico, interpretado a menudo como legitimador de una amplia intervención social de un estado benefactor, al menos si éste es democrático, en favor del interés público; por otro lado, la doctrina de los derechos humanos, usada con frecuencia para tratar de imponer límites morales a la intervención estatal, en favor de la libertad.

Se pretende, por el contrario, recapitular una serie de análisis económico-políticos y actualizar su contrastación sobre el crecimiento de la intervención estatal de la sociedad, sus efectos, sus eventuales límites y los posibles remedios. Partiendo del pensamiento económico y politológico de esta segunda mitad del siglo, el material aquí presentado se remite más bien a un enfoque individualista metodológico (de lejana y vaga raíz utilitaria). Sin embargo, las conclusiones no se identifican con la prescripción intervencionista que a ésta se suele achacar. Más bien se trata de suscitar la reflexión y el debate sobre las implicaciones normativas de tales teorías analíticas.

Así, el material aportado pretende sugerir elementos de respuesta a preguntas como éstas:

- ¿Es la expansión de la actividad del estado inevitable o inexorable?

-¿Tiene algún limite histórico, natural o técnico?

-¿Favorece o perjudica el crecimiento económico?

-¿Está vinculado de algún modo a la igualdad?

-¿Comporta una expansión de la democracia o su reducción? 
El tratamiento es más bien divulgativo y de síntesis, completamente informal, con el único ánimo de suscitar el interés por el tema y el diálogo interdisciplinario.

\section{Los hechos}

El volumen de la intervención del estado y la variedad de ámbitos de la vida económica y social en los que se hace presente han aumentado espectacularmente en los últimos decenios. Hay varias unidades de medida que pueden dar cuenta de este aumento.

La primera, circunscrita a un ámbito de intervención máxima, es la producción económica realizada por las empresas de propiedad estatal. Un ejemplo típico de esta intervención, que ha afectado a todos los países desarrollados, fue el impulso nacionalizador dado por los gobiernos laboristas en Gran Bretaña desde 1945; mediante la apropiación estatal de empresas productoras de bienes privados, como la electricidad, el gas, el carbón, el acero y el transporte, ampliada más tarde a campos como la aeronáutica y la construcción naval, en 1977, es decir, en vigilias de la victoria electoral del programa privatizador de Margaret Thatcher, este conjunto de empresas producía el 13 por 100 del PIB. En otro caso, el de Francia, el acceso al poder de la Unión de la Izquierda en 1981, con un programa nacionalizador, llevó esta producción al 17 por 100 del PIB.

Otra unidad de medida, complementaria de la anterior, puede dar cuenta de aquel tipo de intervención estatal que no absorbe o sustituye totalmente a la iniciativa privada, sino que la limita o coarta mediante regulaciones. La expansión estatal de este tipo que más se ha desarrollado en los últimos decenios incluye al menos dos áreas. Una se refiere a las regulaciones de las actividades económicas, incluidos la concesión de permisos de entrada o creación de nuevas empresas y los controles sobre los precios, productos, servicios ofrecidos, beneficios y mercados a los que sirven las empresas privadas. La otra área son las regulaciones sociales, desarrolladas más recientemente, con objeto de proteger al consumidor, el medio ambiente, los depósitos de los ahorradores y la seguridad en el trabajo o promover una acción afirmativa en favor de las minorías. Hay que tener en cuenta que, en algunos casos, estas regulaciones sociales tienden a eliminar algunas regulaciones económicas y restablecer las condiciones de la competencia de mercado (como, por ejemplo, cuando se trata de defender los derechos del consumidor).

Sin embargo, todas las regulaciones son comparables con otras formas de intervención: así, una licencia discriminatoria para el 
ejercicio de una profesión o la realización de un negocio es equiparable a un subsidio, mientras que la limitación de uso de un terreno, por ejemplo, equivale a un impuesto, cuyos montos serán cargados probablemente en el precio de los productos de las empresas reguladas $\mathrm{y}$, por tanto, podrían también ser medidos en unidades monetarias. También puede conseguirse una aproximación a la medida de su crecimiento de otras dos maneras. Una es la contribución de las empresas reguladas a la producción total: según datos de los Estados Unidos, las empresas privadas reguladas, que producían un 8 por 100 del PIB en 1965, habían alcanzado un 26 por 100 en 1978, en vísperas de la etapa de gobierno desregulador de Ronald Reagan. La otra es la producción legislativa: así, el Registro Federal norteamericano (que no incluye las regulaciones de los estados) había pasado de tener 2.600 páginas dedicadas a regulaciones en 1936 a tener 424.000 páginas en 1970 y 742.000 en 1977.

Una tercera estimación de la actividad estatal puede alcanzarse mediante el número de empleados del estado. La media de los veintiún países capitalistas más desarrollados se sitúa en una proporción de empleados estatales con respecto a la población activa total de alrededor de un 20 por 100 (aunque en algunos países escandinavos ha superado el 30 por 100). En España, en los últimos diez años la proporción se ha acercado a esa media, ya que el número de funcionarios ha pasado de 1,3 millones a 2,1 millones, lo cual significa un aumento del 62 por 100 (mientras que el número de altos cargos casi se ha multiplicado por ocho, pasando de 835 a 6.406).

Por último, la intervención estatal puede ser mesurada en términos monetarios, comparando, por ejemplo, la proporción del gasto público con el producto interior bruto (PIB). Con datos referidos a los países capitalistas más desarrollados, se observa que esta proporción se había mantenido estable dentro de cada país desde mediados del siglo XIX (es decir, desde que hay datos) hasta principios del siglo XX. El crecimiento del gasto público empezó a ser más rápido que el PIB desde 1900, y particularmente desde la Primera guerra mundial, y se aceleró en la segunda mitad del siglo hasta los años ochenta. Como media, la proporción del gasto público sobre el PIB en la Comunidad Europea (9 países) pasó de un 32,3 por 100 en 1960 a un 48,7 por 100 en 1987 (aunque en países como Suecia ha rebasado ampliamente el 60 por 100). En España, en 1960 el gasto público se situaba en un 19,8 por 100 del PIB, en 1975 en un 25 por 100 y en 1990 en un 42,8 por 100 .

Una matización a las medidas anteriores subraya que los términos monetarios de la intervención estatal tienden a sobrevalorarla, ya que ésta es relativamente menor si se mide en unidades físicas de 
producto (horas, kilogramos, metros cuadrados, kilómetros...). Esta desviación procedería de la concentración de la actividad productiva estatal en ciertos sectores que tienen una función de producción trabajo-intensiva, es decir, con altos costes salariales que aumentan más que proporcionalmente con el crecimiento de la renta de la población y más dificultades para incrementar la productividad. Sin embargo, no puede olvidarse que las transferencias monetarias no productivas, que es el tipo de gasto público que más ha aumentado en los últimos decenios, no tienen la característica señalada, de modo que las anteriores unidades de medida deberían ser contempladas como mutuamente complementarias.

(Fuentes de datos: Papeles de Economía Española, 37, 1988; y 38, 1989; International Monetary Fund, 1991; Lane-McKay-Newton, 1991).

\section{Las interpretaciones}

Hay una multiplicidad de interpretaciones teóricas sobre las causas y los factores explicativos del vertiginoso crecimiento que, sobre todo en la segunda mitad del siglo XX, ha tenido la intervención estatal.

Un primer tipo de explicación, hoy poco aceptado, presta especial atención a hechos históricos singulares, como por ejemplo una guerra. Tras ella, los políticos y funcionarios serían capaces de consolidar la concentración de poder y el volumen ampliado de la burocracia aunque hubiera desaparecido el hecho que los había originado (Peacock-Wiseman, 1961). Esta interpretación parece más o menos verosímil si se observan aisladamente los datos de algunos países en los que se disparó la producción estatal y el gasto público durante la Primera y la Segunda guerras mundiales, como Gran Bretaña y los Estados Unidos. Sin embargo, comparando su crecimiento con el de un conjunto más amplio de países, no se encuentra una clara correlación entre el crecimiento de la intervención estatal y su implicación en la Segunda guerra mundial o su neutralidad; incluso, afinando las mediciones, parece haber habido menos crecimiento entre los países que participaron en la guerra que en aquellos que restaron al margen de la misma.

Dos son, de hecho, los principales enfoques actualmente vigentes en la teoría económica para dar cuenta del crecimiento del gasto público. Uno sitúa el origen de su expansión en la demanda de bienes y servicios públicos, y el otro busca la explicación básica en la oferta, es decir, en las motivaciones e intereses de los propios gobernantes. 


\section{La demanda de intervención estatal}

El primer enfoque se basa en gran parte en las teorías de los fallos del mercado para satisfacer de un modo eficiente la demanda de ciertos bienes. Según estas teorías, habría al menos cuatro tipos de actividad en los que la iniciativa privada no podría responder satisfactoriamente a la voluntad de los consumidores potenciales.

El primero es el llamado «monopolio natural». Éste existiría en aquellas actividades en que los costes medios disminuyen a medida que aumenta la producción, es decir, en las que se requiere una alta inversión inicial, y al mismo tiempo existe una demanda limitada. Como consecuencia de ello, en estos sectores (entre los cuales el ejemplo clásico son los ferrocarriles) no caben varias empresas que presentan la misma oferta y son los poderes públicos los que deben encargarse de organizar el suministro. Vale la pena señalar, sin embargo, que en rigor la condición monopólica no puede ser considerada «natural», sino más bien técnica, ya que la forma de la curva de costes puede cambiar con la innovación tecnológica y el tamaño del mercado de un bien puede crecer con un cambio de la renta o de los gustos del público.

El segundo tipo de actividad en el que se suele racionalizar la intervención estatal es aquella que está orientada a la producción de bienes públicos. Quizá sea conveniente aclarar que no se entiende por tales aquellos que son producidos por las empresas públicas (evidentemente, esto implicaría una tautología en la frase anterior), De hecho, unos mismos bienes son producidos alternativamente por la iniciativa privada y por el estado en países de muy parecidos niveles de renta y características culturales (por ejemplo, la electricidad, los viajes aéreos, las bibliotecas, los programas de televisión y un largo etcétera). Se entiende por bienes públicos aquellos que son ofrecidos conjuntamente a los consumidores y que no permiten la discriminación entre éstos, a diferencia de lo que sucede con los bienes privados a través de los precios. Se cuentan entre ellos desde la defensa nacional y la justicia hasta los parques públicos y los programas de televisión no codificados, los acuerdos de los convenios colectivos para fijar salarios y condiciones de trabajo, las carreteras sin peaje y las medidas anticontaminantes, mientras que son bienes privados aquellos que se ofrecen de un modo personalizado y discriminante a los consumidores, como la enseñanza, la atención sanitaria y el suministro de agua corriente.

Dada la posibilidad de que cada individuo acceda al consumo de bienes públicos aun sin haber contribuido a su provisión (mediante la milicia, los impuestos o la acción colectiva), no existe ninguna garantía de que en una sociedad de individuos libres tal contribución 
se lleve efectivamente a cabo. Por ello es posible que, aun en un colectivo cuyos miembros estén sincera e intensamente interesados en el disfrute de esos bienes, predominen los comportamientos de free-rider o gorrón y no se provea la oferta deseada en ausencia de coerción (Olson, 1971).

Un tercer tipo de actividad en la que, a priori, es posible esperar una aceptación social de la intervención estatal es aquel que produce efectos externos (o externalidades) negativos. Entre los ejemplos típicos se hallan la fábrica contaminadora, cuyos humos producen molestias y costes sanitarios a la población circundante, y la línea de ferrocarril, cuyos destellos dañan las cosechas vecinas al trazado. La teoría económica de los derechos de propiedad ha puesto de manifiesto que estos costes sociales también pueden ser sufragados como consecuencia de un acuerdo obtenido por negociación libre entre las partes. De este modo, por ejemplo en la primera situación, o bien se acordaría instalar un filtro en la chimenea pagado por los vecinos, si su precio fuera inferior al de las molestias y la asistencia sanitaria para curar las enfermedades provocadas por el humo, o bien la empresa contaminante indemnizaría a los vecinos si el precio de instalar el filtro fuera mayor. Sin embargo, cualquiera de estos acuerdos requeriría unos altos costes de transacción entre las partes -para negociar, llegar a un pacto y vigilar su efectivo cumplimiento-, por lo que cabría que éstas aceptaran una regulación coercitiva de la emanación de gases si los costes de organización de la misma fueran menores que aquellos costes de transacción (Coase, 1988).

El argumento se completa con la tesis que el nivel de todas estas demandas de intervención estatal es una función positiva del nivel de renta per cápita y de su distribución igualitaria (mientras que el precio relativo de una unidad de servicios públicos y el tamaño de la población influirían en sentido inverso). Esto podría explicar su tendencia a la expansión (el argumento procede de la ley de Wagner 1877, en Musgrave-Peacock, 1958).

En resumen, las teorías de los fallos del mercado proporcionan una racionalidad a ciertas formas de intervención estatal y al consiguiente aumento del gasto público, es decir, les dan una justificación en aras del interés común de la sociedad. Sin embargo, de la racionalidad de tales intervenciones y del hecho de que el estado efectivamente intervenga en la vida económica y social, no se deriva necesariamente que las intervenciones realmente existentes se basen en un deseo de proteger el interés público. De hecho, hay evidencia de muchas intervenciones estatales perniciosas para el crecimiento económico y la eficiencia productiva, que seguramente pueden ser mejor explicadas desde el enfoque de la oferta. 
Además, la demanda resulta sobredimensionada o potenciada cuando la decisión se toma por una vía electoral.

\section{Democracia y redistribución}

Si la decisión sobre la intervención estatal se toma mediante elecciones de los ciudadanos entre programas de partidos que proponen diversas alternativas, es de prever que el nivel de intervención que se alcance esté muy próximo al deseado por el sector decisivo del electorado. Dadas unas ciertas condiciones del sistema político que sería excesivamente prolijo exponer aquí, la teoría supone que, en la mayor parte de los casos, este electorado decisivo será el situado en torno a la mediana de la distribución de preferencias de los electores (genéricamente, un electorado más o menos «centrista» hacia cuyas posiciones tenderán a converger los principales partidos con expectativas de ganar).

Sin embargo, esta posición mediana en el espacio político-ideológico no necesariamente se corresponde con una posición mediana en la distribución de la renta. En general, parece que la desigualdad económica implica que sea mayor el número de ciudadanos con un nivel de renta inferior a la media, de modo que cabe considerar que el votante mediano es más pobre que la media y, por tanto, tenderá a demandar un nivel más alto de intervención estatal, en beneficio propio, que el que sería de esperar por el nivel general de renta per cápita de la sociedad.

Esta tendencia a demandar un nivel alto de intervenciones estatales, con intención redistributiva, crea, además, una dinámica expansiva. La propia disminución de las desigualdades producida por la intervención estatal da, como consecuencia, la elevación del nivel de renta del votante mediano, lo cual genera mayor demanda de intervención. Imaginemos, por ejemplo, una medida como los impuestos progresivos. Éstos aumentan la cuota de impuestos pagada por el votante más rico y reducen la cuota de impuestos pagada por el votante mediano, con lo que aumentan la renta de éste. Dado que la elasticidad de la demanda de intervención estatal con respecto a la renta suele ser superior que la elasticidad de la demanda de intervención estatal con respecto a la cuota de impuestos, el votante mediano aumentará la demanda en una medida superior que la disminución de demanda del votante más rico. Globalmente, una medida redistributiva como ésta hará aumentar, pues, la demanda de intervención estatal y el gasto público.

Por otra parte, la disminución de las desigualdades implica una mayor difusión de la instrucción y la información, la cual favorece 
una percepción más clara de los propios intereses por esos sectores relativamente menos favorecidos y una mayor capacidad de los mismos de expresar sus deseos en la esfera política, bien sea mediante la acción de los grupos de presión, bien mediante una mayor racionalidad de su decisión de voto.

Desde este punto de vista, el crecimiento del gasto público puede ser contemplado como un resultado del crecimiento de los grupos que comparten unos mismos intereses y los pueden identificar y articular. Más concretamente, la expansión de las clases medias (y la nivelación consiguiente de las diferencias de renta entre una amplia parte de la población), así como su percepción de los beneficios de la redistribución, habrían sido una importante fuente de apoyo político a la expansión de la intervención estatal (Downs, 1957; Peltzman, 1980; Meltzer-Richard, 1981; Colomer 1992).

Esta interpretación podría explicar, entre otros muchos hechos recientes, que el gasto público haya crecido más rápidamente en los países desarrollados que en los países subdesarrollados; que, entre los países desarrollados, haya crecido más rápidamente en aquellos en los que han gobernado partidos con políticas más redistributivas, como Suecia, que en los de características contrarias, como los Estados Unidos; que, entre los países subdesarrollados, haya crecido más en aquellos en los que ha habido democracia y niveles educativos más altos que en otros con parecidos niveles de renta; y que en países con pasado autoritario reciente, como Japón o la misma España, haya crecido mucho más con democracia que sin ella.

\section{La oferta estatal}

El otro enfoque teórico interpreta algunas de las correlaciones anteriormente mencionadas con un signo inverso de causalidad. Según éste, no se trataría tanto de que la demanda empuje la intervención estatal y luego ésta tenga efectos no intencionados más o menos perversos, como de que los gobernantes -básicamente, los políticos profesionales y los altos funcionarios- la haga crecer en su propio beneficio, aun en detrimento de los intereses más comunes de la sociedad.

Este enfoque requiere adoptar como punto de partida unos supuestos de motivaciones autointeresadas, no sólo de los ciudadanos, los votantes y los grupos de presión -como se hace implícitamente en el enfoque anterior-, sino también de los gobernantes. Es decir, supone admitir que las motivaciones básicas de los seres humanos no se dividen en dos grupos, según si gozan o están privados de los placeres del poder estatal, sino que son fundamentalmente las 
mismas, es decir, deseos de riqueza, prestigio, poder y estatuto, con unos u otros énfasis según cuál sea su campo específico de actividad.

No hay duda de que, desde este punto de vista, la motivación básica de los políticos profesionales debe de ser la conquista, el mantenimiento y la ampliación del poder político a su disposición, aun en el caso de que éste sea concebido como un simple instrumento al servicio de otros objetivos (como, por ejemplo, la realización de unos ideales éticos). Entendiendo que poder significa tener la capacidad de provocar acciones ajenas que no se producirían de otro modo, es importante comprender que la disposición de votos, recursos humanos, capacidad legislativa, aparato administrativo y fondos financieros, está en la constitución misma del poder. Así, y aun siendo una definición parcial, cabría aceptar, por ejemplo, la veracidad incluida en la máxima según la cual «mandar es gastar».

Obsérvese que, en algunas de las medidas de la intervención estatal proporcionadas al principio de esta comunicación, hemos subrayado su crecimiento relativo (producción y gasto público sobre el PIB, funcionarios sobre la población activa), pero, dado que las variables de referencia (PIB, población activa) también han crecido de un modo continuado a lo largo del siglo, de hecho la dimensión de los recursos a disposición de los gobernantes han crecido aún más de lo que los datos relativos indican. Concretamente, cabe estimar que los recursos financieros a disposición de los gobernantes del estado español en 1992 deben de haberse al menos triplicado en relación con los de 1976.

El otro hecho relevante en este enfoque es la reproducción en la esfera estatal de la separación entre propiedad y control, característica de la gran empresa privada moderna. Así como existe un vínculo electoral entre los ciudadanos y los políticos electos (e indirectamente los cargos de elección indirecta o designación digital por éstos), no se da ninguna forma de control comparable con respecto a los funcionarios que llevan a cabo las decisiones públicas y administran los recursos correspondientes. La asimetría entre político y burócrata es muy notable, ya que, si bien del primero depende la distribución del presupuesto entre las diversas áreas de la administración, el segundo goza de una posición monopólica en la provisión de los recursos administrativos, en la asignación de capital y trabajo para la producción de los bienes o la prestación de los servicios demandados e incluso en la disponibilidad de información sobre esta asignación.

Se establece así una interrelación a través de la cual cada sector de la burocracia extrae presupuesto de los políticos para sus oficinas, departamentos y agencias y los políticos consiguen la prestación de los bienes y servicios demandados por el público, rentables electoralmente, pero a menudo muy ineficientes en comparación con el 
óptimo que se alcanzaría en una situación de competencia perfecta. Si los políticos y los burócratas persiguen sus propios intereses, la asimetría mencionada facilita la expansión del gasto y del personal funcionario (Niskanen, 1971; Orzechorski, 1977).

\section{¿Tiene un límite la expansión estatal?}

De algunos de los análisis anteriormente presentados cabría inferir la expectativa de que la intervención estatal tienda a expandirse sólo hasta un cierto nivel, del que incluso podría sospecharse que en algunos países más desarrollados ya se habría alcanzado.

Por un lado, algunos autores han argumentado que el aumento de la renta produce un aumento menos que proporcional del gasto público, de modo que habría un límite al antes mencionado crecimiento relativo (aunque no al crecimiento absoluto, como acabamos de decir) del gasto público con respecto a la renta.

Por otro lado, está establecido que la igualación de las rentas hace aumentar la demanda de intervención estatal, pero, según otros analistas, a partir de un cierto nivel de igualdad este aumento de la demanda desaparecería. En las sociedades más desarrolladas, al haberse nivelado relativamente las rentas y haber disminuido las posibilidades de aumentar la educación de la población (precisamente porque la escolarización se ha universalizado hasta hacer a todos suficientemente capaces de darse cuenta de cuáles son sus intereses), la presión para que continúe la expansión del gasto público disminuiría. Así, cabría prever un mayor crecimiento de la intervención estatal en los países subdesarrollados que en los desarrollados (excepto en países como el Japón, donde la reducción de desigualdades es reciente, y siempre dependiendo del volumen que alcancen las oleadas migratorias hacia los países desarrollados de sectores de población en situación de pobreza y sin escolarizar).

Otra línea de razonamiento llama la atención sobre el carácter moderador del gasto público que tiene la descentralización de los estados. El argumento parte de la tesis de que, si hay centralización, no hay competencia entre sectores de la administración y la burocracia tiene por ello más capacidad de conseguir la expansión del presupuesto, mientras que, por el contrario, la descentralización mejoraría la eficiencia y, por tanto, reduciría el tamaño de la intervención estatal.

De este modo, con el crecimiento de la renta aparecerían dos tendencias contradictorias. Por una parte, la tendencia ya mencionada a que un aumento de la renta provoque un aumento general de la demanda y del gasto público. Por otra parte, la tendencia a que un aumento de la renta provoque un aumento mayor de la demanda de 
servicios de tipo personal, más propios de las administraciones subcentrales, de modo que induzca una mayor descentralización financiera y, a través de ella, una mayor eficiencia y una disminución del gasto público total (Castells, 1991).

Sin embargo, no hay una evidencia empírica concluyente de esta relación. En los Estados Unidos, por ejemplo, la centralización (medida por la proporción de gasto federal sobre gasto público total) ha aumentado desde 1900, pero una gran parte de este aumento se produjo antes de la Primera guerra mundial, es decir, antes del inicio del crecimiento continuado del gasto público. En la segunda postguerra, en cambio, ha aumentado ligeramente la descentralización mientras el gasto público se disparaba. En la España de los años ochenta, sin ir más lejos, es evidente que han aumentado visiblemente la descentralización y el gasto público a la vez.

Con respecto a las teorías de la oferta, y en particular sobre el papel motor de la expansión del gasto público que desempeña la burocracia, cabe señalar dos factores que limitan esta expansión. Una es la intolerancia del político al déficit financiero de la agencia o departamento administrativo bajo su jurisdicción. De acuerdo con ello, la expansión ineficiente de la actividad estatal puede llegar hasta el punto en que los beneficios públicos de la misma queden completamente absorbidos por la administración, pero no más allá. No es difícil demostrar formalmente que este nivel máximo implica un volumen de producción o gasto público igual al doble del que se daría en una situación de competencia perfecta. El otro factor es la elasticidad de los votos al gasto público del gobierno saliente, la cual puede provocar la intervención controladora del político sobre el burócrata antes de que se haya alcanzado el límite que acabamos de mencionar.

(Nota. Puede ser interesante señalar que, midiendo la actividad estatal mediante porcentajes del gasto público sobre el PIB, no hay garantía de que se vaya a alcanzar ningún límite, ni siquiera del $100 \%$. Así, por ejemplo, las transferencias estatales, como becas, pensiones y subsidios, pueden ser sometidas a impuestos, aunque sea incorporándolas al monto total de la renta del individuo o la familia, con los cuales es posible financiar nuevas transferencias. De hecho, en Israel se ha rebasado este límite contable.)

\section{Las consecuencias}

En algunas ideas mencionadas al dar cuenta de los análisis explicativos sobre el crecimiento de la intervención estatal ya se ha aludido a sus consecuencias sobre la eficiencia económica, la igualdad y la democracia. 
En general, existe un acuerdo relativamente amplio en valorar la expansión del gasto público como un factor negativo para el crecimiento económico (Buchanan-Wagner, 1977; Landau, 1985 Spann, 1977).

Por un lado, la producción estatal suele implicar la existencia de un monopolio en su rama o sector de actividad, lo cual comporta un nivel de producción inferior y un precio superior a los de mercado. La separación entre políticos y burócratas y la tendencia de éstos a absorber los beneficios públicos en gastos administrativos y de personal, acentúan la ineficiencia de ese monopolio.

Por otro lado, la regulación procede en muchos casos de la captura del gobierno por los grupos de interés, obtenida a cambio de favores políticos. La teoría de la acción colectiva muestra que son los miembros de los grupos pequeños los que tienen mayores incentivos para organizarse y presionar, hasta imponer «la explotación del grande por el pequeño», es decir, el decantamiento de la intervención estatal a favor de intereses minoritarios en la sociedad (Stigler, 1975; Becker, 1983).

También en el terreno electoral se puede apreciar este decantamiento, sobre todo si la sociedad es compleja y el sistema de partidos simple, ya que en tales situaciones, y en general siempre que las votaciones no son por temas sino por conjuntos globales de los mismos, suele ser rentable electoralmente confeccionar programas partidistas por agregación de intereses mayoritarios e intereses minoritarios (Downs, 1957; Colomer, 1992).

Parece, pues, que, si cada uno de los actores relevantes en el proceso de decisión pública está motivado por la satisfacción de su propio interés, tiende a producirse una coalición entre los grupos de presión minoritarios, los gobernantes electos y los burócratas en favor de la expansión de la actividad del estado, a menudo a costa de los intereses de eficiencia y prosperidad económica de la mayoría de la sociedad.

Con respecto a la igualdad, ya hemos expuesto el carácter redistributivo que tienen muchas de las intervenciones estatales, bien a favor de una reducción de las desigualdades, según el enfoque de la demanda, bien a favor de minorías relativamente privilegiadas en el enfoque de la oferta. Ambas apreciaciones pueden ser hasta cierto punto compatibles si se acepta que una gran parte de los beneficiarios de los servicios públicos creados en los últimos decenios han sido sectores de las clases medias, lo cual provoca una reducción de la medida global de la desigualdad en la sociedad, pero sigue dejando relativamente insatisfecha a una mayoría de ciudadanos que se encuentran en inferiores condiciones de vida. En cualquier caso, es relevante señalar la contradicción entre los efectos redistributivos y 
las potencialidades futuras de crecimiento $\mathrm{y}$, por tanto, de mejora general del nivel de vida de la sociedad.

Por último, pero no menos importante, parece muy claro que la expansión de la actividad estatal tiene efectos negativos sobre la democracia, sobre todo por causa del aumento de la autonomía de decisión de la clase política que conlleva. Puede sostenerse incluso que el deterioro contemporáneo de la viveza de la vida democrática en muchos países, simultanea a la expansión del estado y a la difusión de los regímenes democráticos en el mundo, ha implicado una refutación de muchas de las promesas originarias de los clásicos de la teoría democrática en los que algunos habían querido fundar su legitimidad, al menos en lo que se refiere a las ideas de autogobierno o soberanía popular.

Dicho en pocas palabras, el crecimiento del volumen, de la variedad de áreas de competencia y de la complejidad de las decisiones públicas apenas ha ido acompañado de la menor innovación en las formas y oportunidades de participación política de los ciudadanos, que siguen concentradas en el voto infrecuente y global. Este desfase provoca que el elector, a la hora de elegir partido, tenga que decantarse en función de la posición programática que se le ofrece en algún tema particular o de alguna otra característica de la candidatura (incluidas, por ejemplo, su fiabilidad democrática o las condiciones del candidato), considerada prioritaria para el ciudadano, a pesar de su probable desacuerdo o ignorancia sobre las posiciones de ese partido, o las líneas de gobierno que verosímilmente introducirá en caso de vencer, en muchos otros temas. Ello tiende a provocar, lógicamente, insatisfacción con muchos aspectos de la gestión pública entre los propios votantes del partido en el gobierno y, en general, produce la sensación de dar a los gobernantes un enorme margen de decisión autónoma, no emanada del mandato de los electores.

La desproporción entre el gran poder real de toma de decisiones de los gobernantes y la pequeña influencia de los ciudadanos en las mismas se agrava si concurren otros factores, como por ejemplo, la mayoría parlamentaria absoluta de un solo partido, el incumplimiento de las pocas promesas electorales claras y concretas con las que el elector se ha podido identificar al emitir su voto, o la corrupción.

Nos detendremos brevemente en este último aspecto. Dejando de lado la falacia de identificar los comportamientos ilegítimos con aquellos que están penalizados en un código vigente en unos concretos momento y lugar, entendemos por corrupción al menos tres tipos de comportamientos.

Primero, la obtención de un privilegio, beneficio o ventaja privada mediante un uso de recursos públicos no sometido a la decisión o control democrático (incluidas la directa apropiación privada de bienes 
estatales y el tráfico de influencias). La oportunidad de este tipo de comportamientos aumenta con el monto de los recursos públicos y con las motivaciones egoístas de los gobernantes, las cuales se acentúan cuando la clase política en el gobierno es improvisada y sin cualificar, el ejercicio legal de la política profesional tiene pocos incentivos económicos y hay pocas reglas de control.

Segundo, la obtención de recursos privados para la financiación de los partidos mediante un uso, análogo al tipo anterior, de recursos públicos no sometidos a control. Este comportamiento puede darse con mayor probabilidad cuando las motivaciones estrictamente egoístas de los políticos son sustituidas por el patriotismo de partido o la militancia intensiva.

Tercero, la obtención de recursos o beneficios públicos mediante una apropiación estatal de recursos privados no sometida a decisión o control democráticos. Un ejemplo de este tipo sería la apropiación pública de plusvalías inmuebles creadas por una intervención estatal, actuación que no suele ser paralela a la apropiación de las minusvalías que crea también a menudo esa intervención. Así, tanto si la intervención estatal crea externalidades positivas como si las crea negativas, siempre es el agente económico privado el más perjudicado, bien sea por expropiación, bien por estatalización del negocio potencial inducido por aquella intervención.

En estos dos últimos casos, en los que el beneficiario previsto es un partido o una institución pública, también cabe que algunos intermediarios obtengan un beneficio privado. Es conveniente señalar, sin embargo, que sólo se supone un comportamiento corrupto de ciudadanos privados en este último caso de intermediación autointeresada y en algunos casos de tráfico de influencias, mientras que en todos los tipos de corrupción mencionados se da por supuesta la intervención de políticos o funcionarios que violan las reglas de decisión democráticas.

La corrupción no es, pues, siempre perjudicial para las condiciones de eficiencia del proceso económico. De hecho, algunas apropiaciones estatales de plusvalías, por ejemplo, pueden ser beneficiosas para el resto de la sociedad, o al menos tener un efecto redistributivo, mientras que otras pueden ser perjudiciales. En otros casos, la evaluación resulta dudosa o relativa a quien la haga, como en el caso de que el objeto de la acción sea rellenar las arcas de los partidos con el fin de incrementar su propaganda. Lo que sí que en cualquier caso resulta perjudicado por la corrupción es la igualdad democrática de derechos de los ciudadanos, ya que los comportamientos mencionados siempre implican arbitrariedad.

Este desfase entre el alcance de las decisiones públicas tomadas por los gobernantes en el seno de las instituciones y la escasez y 
simplicidad de la intervención ciudadana en las mismas, ha desgarrado a los viejos partidos «de masas» e ideológicos, donde se agregaban demandas ciudadanas ampliamente representativas en torno a programas con posiciones políticas coherentes en los distintos temas. En gran parte, ésta es una de las causas de que muchos partidos, y particularmente en aquellos lugares, como España, donde la tradición democrática es escasa, tiendan a estar formados muy mayoritariamente por profesionales de la política o aspirantes a serlo. Así aumenta la confrontación entre la «clase política» y los funcionarios con respecto a la ciudadanía, entre gobernantes y gobernados. Mientras los ciudadanos incrementan su incomodidad con respecto a los políticos, éstos alimentan la sensación de que, muchas veces, «gobernar es resistir».

\section{Remedios}

Hay dos tipos de respuesta posibles a los procesos recientes de expansión de la ineficiente y no controlada democráticamente intervención estatal.

La primera respuesta, habitualmente llamada «neoliberal», consiste en disminuir la intervención estatal; es decir, en llevar a cabo una serie de privatizaciones y desregulaciones e introducir criterios de competencia en el seno de la administración (Swann, 1988).

Más concretamente, se incluyen en esta orientación las medidas destinadas a sustituir las decisiones no controladas pero vinculantes de políticos y altos burócratas por los acuerdos pactados entre agentes privados en el mercado; a aumentar la eficiencia de la administración pública mediante concursos internos entre diversos departamentos de la administración o entre empresas públicas y empresas privadas para la adjudicación de contratos para la prestación de servicios; a incentivar la productividad de los burócratas y funcionarios mediante remuneraciones diferenciales como las que se usan habitualmente en la empresa privada; a disminuir los gastos y el financiamiento público de los partidos e introducir mayor control sobre sus finanzas.

Estas medidas pueden producir un aumento de la eficiencia, aunque no necesariamente de la igualdad o de la democracia: disminuyen las distorsiones introducidas por el procedimiento democrático de decisión, pero no siempre mejoran la representatividad social de las decisiones y a menudo crean nuevas externalidades.

No hay duda, de todos modos, de la coherencia teórica de este proyecto, que ha inspirado en parte a muchos gobiernos democráticos en los años ochenta. En la práctica, junto a algunos resultados 
exitosos, otros insuficientes y otros perversos y no-intencionados, tal vez lo más importante que esta experiencia neoliberal ha mostrado es que no hay nada de inevitable ni inexorable en el crecimiento de la actividad estatal. De hecho, hoy es más fácil darse cuenta de que, en Europa, la intervención del estado disminuyó o estuvo estancada durante el siglo XIX y ha crecido en el siglo XX, sobre todo en su tercer cuarto. Así como en estos últimos años parece haberse producido una tendencia a la desaceleración de su crecimiento, es desde luego posible en el futuro su reducción.

La segunda respuesta, a la que quizá cabría llamar «neodemocrática», sería aquella que tendiese a hacer posible una participación más frecuente y pormenorizada de los ciudadanos en las decisiones públicas, sin por ello aumentar excesivamente los costes de la acción. Los modernos medios telemáticos, telefónicos y televisivos permiten una innovación en este terreno sin parangón con lo que ha sido la práctica de los regímenes representativos en los últimos trescientos años. Los partidos, las elecciones de representantes y los parlamentos podrían desempeñar de este modo un papel más activo en la selección y énfasis de problemas y en la presentación de programas y alternativas, pero sin monopolizar en sus estrechos cauces las oportunidades de intervención de los ciudadanos en la toma de decisiones.

Tal vez también podría encontrarse un óptimo en una combinación de las dos orientaciones mencionadas, es decir, en un proyecto de democracia austera que fuera más capaz de promover a la vez la prosperidad y la participación de los ciudadanos. Es, en todo caso, una tarea que queda por hacer.

\section{BIBLIOGRAFÍA}

William J. Baumol: Macroeconomics of Unbalanced Growth, «American Economic Review», 57, junio 1967.

Thomas E. Borcherding (ed.): Budgets and Bureaucrats: The Sources of Government Growth, Duke University Press, Durham N. C., 1977.

James M. Buchanan y R. E. Wagner: Democracy in Deficit: The Political Legacy of Lord Keynes, Academic Press, New York, 1977.

Antoni Castells: Factores explicativos del gasto público: una aproximación empírica, Instituto de Estudios Fiscales, Madrid, 1991.

Ronald Coase: The Firm, the Market, and the Law, The University of Chicago Press, 1988.

Josep M. Colomer (ed.): Lecturas de teoría política positiva, Instituto de Estudios Fiscales, Madrid, 1992.

Anthony Downs: An Economic Theory of Democracy, 1957 (trad. cast., Teoría económica de la democracia, Aguilar, Madrid, 1973). 
International Monetary Fund: Government Finance Statistics Yearbook.

Daniel L. Landau: Government Expenditure and Economic Growth in the Developed Countries: 1952-76, «Public Choice», 47, 1985.

Jan-Erik Lane, David McKay, and Kenneth Newton: Political Data Handbook. OECD Countries, Oxford University Press, 1991.

R. A. Musgrave y A. T. Peacock (eds.): Classics in the Theory of Public Finance, Macmillan, Londres, 1958.

William H. Niskanen: Bureaucracy and Representative Government, Aldine-Atherton, Chicago, 1971.

Mancur Olson: The Logic of Collective Action, Yale University Press, 2. ${ }^{\circ}$ ed., 1971.

William Orzechowski: Economic Models of Bureaucracy: Survey, Extensions, and Evidence, in Borcherding, 1977.

Papeles de Economía Española: «El gasto público en la democracia», 37, 1988.

— «La empresa pública en España», 38, 1989.

Sam Peltzman: The Growth of Government, «The Journal of Law and Economics», xiii, 2, octubre 1980.

Robert M. Spann: Public versus Private Provision of Governmental Services, in Borcherding, 1977.

- The Macroeconomics of Unbalanced Growth and the Expanding Public Sector, «Journal of Public Economics», diciembre 1977.

George Stigler: The Citizen and the State, The University of Chicago Press, 1975.

Dennis Swann: The Retreat of the State. Deregulation and Privatisation in the UK and US, Harvester-Wheatsheaf, New York-London, 1988. 